\title{
Zeit- und Festrechnung 1956
}

Das Jahr 1956 entspricht dem Jahr 6669 der Julianischen Periocle und dem Jahr 7464-7465 der Byzantinischen Ära.

\section{Gregorianischer Kalender}

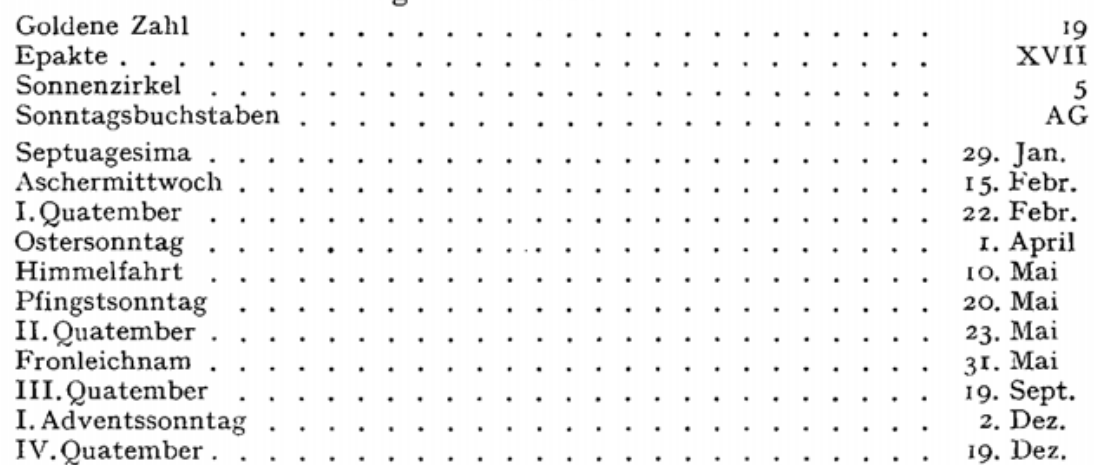

\section{Dimensionen der Erde}

$\begin{array}{llll}\text { Große Halbachse } & a=6377397.155 \mathrm{~m} & \log a=6.8046434637 \\ \text { Kleine Halbachse } & b=6356078.963 \mathrm{~m} & \log b=6.803 \text { I } 892839 \\ \text { Abplattung } & \mathfrak{a}=1: 299.1528129 & \log \mathfrak{a}=7.5241069092-10 \\ \text { Meridianquadrant } & =10000855.76 \mathrm{~m} & \end{array}$

Die Maßeinheit der Lănge ist das legale Meter.

b) Nach Ha y ford (1909)

identisch mit Internationalem Ellipsoid (1924)

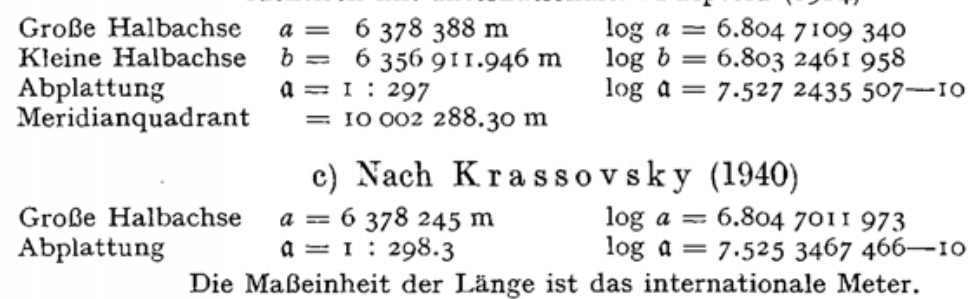

Ein internationales Meter $=0.9999866$ legales Meter.

Will man die Länge einer in legalen Metern gemessenen Strecke in internationalen Metern angeben, so hat man die Anzahl der legalen Meter mit 1.000 or 34 zu multiplizieren.

Normalwert für die Schwerebeschleunigung im Meeresniveau :

$\gamma_{0}=978.030\left(\mathrm{I}+0.005302 \cdot \sin ^{2} \%-0.000007 \cdot \sin ^{2} 2\right.$ \% $) \mathrm{cm} \cdot \mathrm{sec}^{-2} \cdot($ Helmert I901)

$\gamma_{0}=978.0490\left(\mathrm{I}+0.0052884 \cdot \sin ^{2} \cdot \mathrm{p}-0.0000059 \cdot \sin ^{2} 2 \%\right) \mathrm{cm} . \mathrm{sec}^{-2}$. (Cassinis 1930$)$

Masse der Erde: $5.974 \cdot 10^{27} \mathrm{~g}$

Masse der Sonne: $1.983 \cdot 10^{33} \mathrm{~g}$

Radius der Sonne: $695300 \mathrm{~km}$

Mittlere Entfernung Erde-Sonne: $149504200 \mathrm{~km}$

Lichtzeit für die mittlere Entfernung Erde-Sonne: $498^{\mathrm{S}} \cdot 72$ (mit Lichtgeschwindigkeit $299774 \mathrm{~km} / \mathrm{sec}$.) 